\title{
BLUFF-BODY FLAMES IN HOT AND DILUTED ENVIRONMENTS
}

\author{
Chengyu Liu \\ LNM, Institute of Mechanics, Chinese Academy of \\ Sciences \\ Beijing, 100190, China \\ Tao Yang \\ LNM, Institute of Mechanics, Chinese Academy of \\ Sciences \\ Beijing, 100190, China
}

\author{
Jian Zhang * \\ LNM, Institute of Mechanics, Chinese Academy of \\ Sciences \\ Beijing, 100190, China \\ *Corresponding author: zhangjian@Inm.imech.ac.cn \\ Yanhong Ma \\ School Energy \& Power Engineering, Beihang \\ University, Beijing, China
}

\begin{abstract}
Large eddy simulation/Flamelet progress variable approach is employed in current research to investigate how flame behaviour is influenced by bluff-body and coflow composition. We used Sydney bluff-body burner as the target burner. Computation grid in cylinder coordinates is approximately 2.7 million in total number, extended to the downstream location 80 times of jet diameter. Three coflow compositions with different oxygen ratio at the same inlet velocity are considered. Comparing to jet flames with hot and diluted coflow, instantaneous and statistical results showed that an introduction of bluffbody preheats the fuel and shortens the flame length. At lower oxygen ratio condition, a weaker reaction zone emerged, marked by lower temperature and $\mathrm{OH}$ concentration; the flame appeared lifted gradually, leading to a potential MILD combustion. Besides, bluff-body effect behaves differently in these flames: at lower oxygen ratio condition, a large-scale distribution of $\mathrm{CH}_{2} \mathrm{O}$ appeared as a marker of partial premixing and preignition reaction in recirculation area; on the contrary, in higher oxygen ratio case, the recirculation area brings out more reactive fuel at lower speed and higher temperature, hence ignitable in the vicinity of bluff-body.
\end{abstract}

\section{INTRODUCTION}

Bluff-body is widely applied in numerous combustion facilities like boilers and gas turbines, since the advantage of expanded stability limits of non-premixed flames. Sydney bluff-body flame [1-2] becomes a standard target flame in consideration of well-defined geometry of the burner and its similarity to practical combustors. Vortex shedding and largescale recirculation [3-4] are known to keep flame stable in backward facing step and bluff-body wakes. Meanwhile, several flame modes were discovered [45], conditioned with varying air-fuel velocity ratio, which depends on different mixing characteristics in the recirculation zone.

Hot and diluted environments are used in various thermal engines to increase thermal efficiency and decrease the pollutant emission with hot exhaust recirculation employed. Experiments [6-7] on jet flames under these configurations discovered that differences of thermal properties and composition of coflow result in distinct flame structure and stabilization mechanism of these flames. In experimental furnaces [8], the overall flow includes a large circulation mode, leading to a quasi-bluff-body effect stabilizing the flames.

The objective of current research is to investigate bluff-body flame behavior in hot and diluted environments. With three coflow composition of various oxygen ratio, we aim to investigate the influence of bluff-body on flames in hot and diluted environments.

\section{NUMERICAL METHODOLOGY AND COMPUTATIONAL SETUP}

Large eddy simulation/Flamelet progress variable approach is employed in current research. The introduction of progress variable enables the 
flamelet model to replicate extinction and re-ignition [9-11]. This approach has been proven reliable in computing flames in similar thermal conditions, including lifted flames in VCB [12-13] and three-stream attached flame in JHC burner [6-7,14]. Favre-filtered N$S$ equation and transport equations of mixture fraction $Z$ and progress variable $C$ are solved in this paper:

$$
\begin{aligned}
& \tilde{\mathrm{D}}_{t} \bar{\rho}=-\bar{\rho} \nabla \cdot \tilde{\boldsymbol{u}} \\
& \bar{\rho} \tilde{\mathrm{D}}_{t} \tilde{\boldsymbol{u}}=-\nabla \bar{p}+\nabla \cdot \overline{\bar{\sigma}}+\nabla \cdot \overline{\bar{\sigma}}^{r e s}+\bar{\rho} \mathbf{g} \\
& \bar{\rho} \tilde{\mathrm{D}}_{t} \tilde{Z}=-\nabla(\bar{\rho} \tilde{\alpha} \nabla \tilde{Z})+\nabla \cdot \overline{\boldsymbol{\tau}}_{Z}^{r e s} \\
& \bar{\rho} \tilde{\mathrm{D}}_{t} \tilde{\boldsymbol{C}}=-\nabla(\bar{\rho} \tilde{\alpha} \nabla \tilde{\boldsymbol{C}})+\nabla \cdot \overline{\boldsymbol{\tau}}_{C}^{r e s}+\bar{\rho} \tilde{\dot{\omega}}_{C} \\
& \overline{\bar{\sigma}}=2 \bar{\rho} \tilde{\boldsymbol{v}}\left(\underline{\underline{S}}-\frac{1}{3}(\nabla \cdot \tilde{\boldsymbol{u}}) \underline{\underline{I}}\right) \\
& \overline{\bar{\sigma}}^{r e s}=\bar{\rho} \tilde{\boldsymbol{u}} \tilde{\boldsymbol{u}}-\bar{\rho} \boldsymbol{u u} \\
& \overline{\bar{\tau}}_{\psi}^{r e s}=\bar{\rho} \tilde{\boldsymbol{u}} \tilde{\psi}-\bar{\rho} \boldsymbol{u} \psi
\end{aligned}
$$

where the residuals are all modelled by dynamic Smagorinsky model

A dual-stream configuration targeting Sydney bluff-body burner, of which the diameter of central jet is $4.6 \mathrm{~mm}$, is utilized in this paper, using a grid number of $256 \times 162 \times 64$ in cylinder coordinates system, which has been proved effective in repeating major characteristics previously discovered of bluffbody flame in conventional cases [15]. Three coflow conditions at the same temperature $(1200 \mathrm{~K})$ are considered, with volumetric ratio of oxygen at $6 \%$, $9 \%$ and $12 \%$. The rest composition of the coflow is made up of $10 \% \mathrm{H}_{2} \mathrm{O}, 3 \% \mathrm{CO}_{2}$ and nitrogen. Methane and hydrogen at equivalent volume at $305 \mathrm{~K}$ is taken as the fuel in the high-speed central jet. Velocity inlet conditions are the same with previous experiments HM1e[16], which is carried out under ambient room temperature.

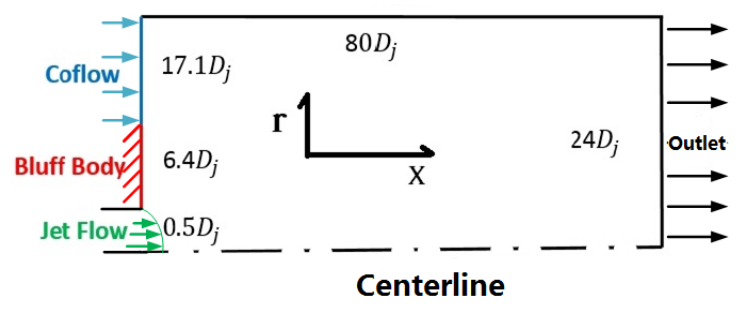

Figure 1 Schematic of computation domain

\section{RESULTS AND DISCUSSIONS}

Simulation results revealed in this paper are computed from stationary initial field with no stable flames. As a result, the three flames were found lifted downstream of the neck zone. Lower coflow speed is therefore adopted to ignited mixture in the recirculation zone to emulate practical burning state in experimental furnaces and industrial device.
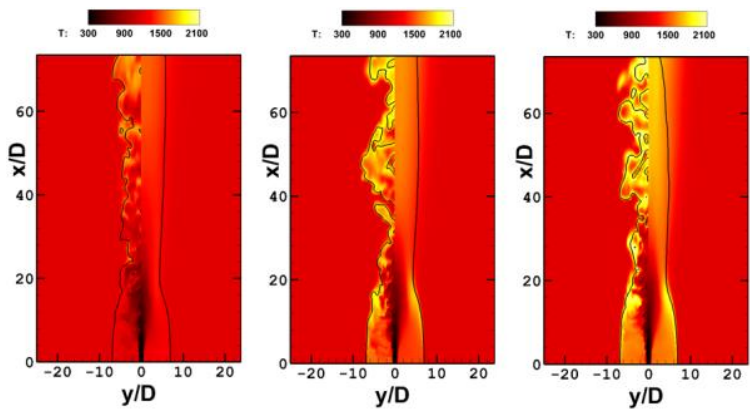

Figure 2 Instantaneous (left half) and statistical mean (right half) temperature contour of flames at coflow oxygen ratio $6 \%(b), 9 \%(b), 12 \%(c)$. The black line stands for the stoichiometric mixture fraction.

Figure 2 displays temperature contour of the three flames. Previous simulation [17] pointed out that under 9\% oxygen condition, the flame is lifted under lower central jet and coflow speeds. Whereas the mixture in recirculation zone is surely ignited, similar to bluffbody flames under ordinary thermal conditions in stabilizing flames, further proven by hydroxyl mass fraction displayed in Figure 3.
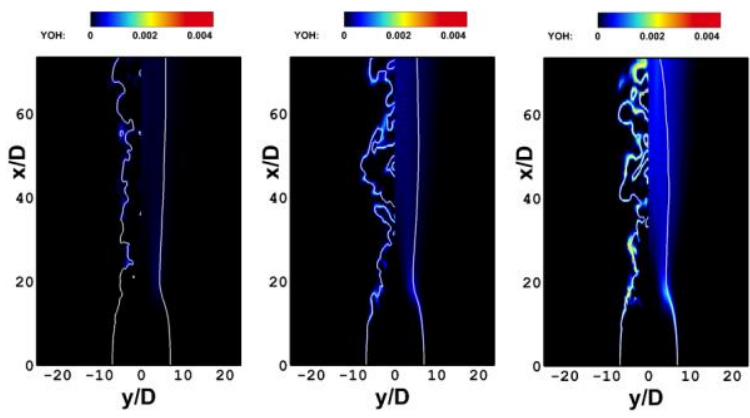

Figure 3 Instantaneous (left half) and statistical mean (right half) mass fraction of hydroxyl contour of flames at coflow oxygen ratio $6 \%(\mathrm{~b})$, $9 \%(b), 12 \%(c)$. The white line stands for the stoichiometric mixture fraction.

As oxygen ratio in coflow composition inclines, maximum temperature in the computational domain rises. The flame behaves like MILD combustion at $6 \%$ oxygen case, since the reaction zone marked by high temperature and hydroxyl becomes distributed and the temperature rises moderately. Besides, the flame is more stretched when more oxygen is supplied, together with flame pockets appear in the fuel-rich side, possibly indicating large proportion of 
local extinction and re-ignition. However, due to larger ratio of oxygen in coflow, the stoichiometric mixture fraction gets bigger, which might explain a portion of flame pockets appearances.
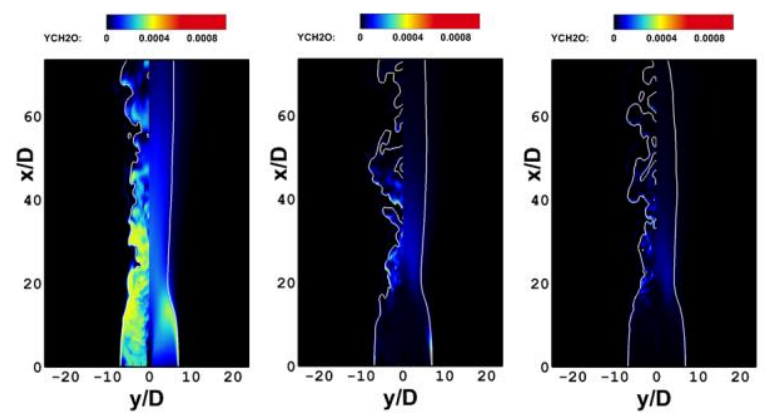

Figure 4 Instantaneous (left half) and statistical mean (right half) mass fraction of formaldehyde contour of flames at coflow oxygen ratio $6 \%(b), 9 \%(b), 12 \%$ (c). The white line stands for the stoichiometric mixture fraction.

Formaldehyde was generally considered a marker of preignition reaction in hot and diluted environments. Figure 4 shows that obvious distribution of formaldehyde in the recirculation zone in the lowest oxygen ratio case, comparing to

\section{ACKNOWLEDGEMENTS}

The investigations presented in this paper have been supported by National Natural Science Foundation of China under contract 51376190, 11572330. The authors also acknowledge National Supercomputer Centre in Tianjin for providing computational resource.

\section{REFERENCES}

1. Dally, B. B., Fletcher, D. F., \& Masri, A R. (1998). Flow and mixing fields of turbulent bluff-body jets and flames. Combust. Theory Modell, 2(2), 193-219.

2. Masri, A. R., \& Bilger, R. W. (1984). Turbulent Diffusion Flames of Hydrocarbon Fuels Stabilized on a Bluff Body. 20th Symposium (International) on Combust., 319-326.

3. Raman V. and Pitsch H. (2005). Large-eddy simulation of a bluff-body stabilized non-premixed flame using a recursive filter-refinement procedure. Combust. Flame, 142(4), 329-347.

4. Yang J. T., Chang C. C., and Pan, K. L. (2002). Flow structures and mixing mechanisms behind a disc distribution in the vicinity of the stoichiometric line in the other cases. Therefore, recirculation zone in this very case accommodates the preignition reaction. As for the larger coflow oxygen ratio, the mixture has been ignited ahead of the neck zone, which stands that the moderate preigntion reaction doesn't exist in the recirculation zone. However similar to the jet lifted flames, formaldehyde still appears on the fuelrich side downstream of the recirculation zone, suggesting the incompleteness of reaction of the mixture.

\section{CONCLUSIONS}

As for the effect of coflow composition with current configuration, a weaker reaction zone emerged at lower oxygen ratio condition, marked by lower temperature and $\mathrm{OH}$ concentration; the flame appeared lifted gradually, leading to a potential MILD combustion. Besides, at lower oxygen ratio condition, a large-scale distribution of $\mathrm{CH}_{2} \mathrm{O}$ appeared as a marker of partial premixing and preignition reaction in recirculation area; on the contrary, in higher oxygen ratio case, the recirculation area brings out more reactive fuel at lower speed and higher temperature, hence ignitable in the vicinity of bluff-body.

stabilizer with a central fuel jet. Combustion Sci. Tech., 174(3), 93-124.

5. Yang J. T., Chang C. C., Pan K. L., Kang Y. P., and Lee Y. P. (2002). Thermal analysis and PLIF imaging of reacting flow behind a disc stabilizer with a central fuel jet. Combust. Sci. Tech., 174(3), 71-92

6. Medwell, P. R., Kalt, P. A. M., \& Dally, B. B. (2008). Imaging of diluted turbulent ethylene flames stabilized on a Jet in Hot Coflow (JHC) burner. Combust. Flame, 152(1-2), 100-113. http://doi.org/10.1016/j.combustflame.2007.09.003

7. Medwell, P. R., \& Dally, B. B. (2012). Effect of fuel composition on jet flames in a heated and diluted oxidant stream. Combust. Flame, 159(10), 31383145.

8. Li, P., Dally, B. B., Mi, J., \& Wang, F. (2013). MILD oxy-combustion of gaseous fuels in a laboratory-scale furnace. Combust. Flame, 160(5), 933-946.

9. Pitsch, H. (2006). Large-Eddy Simulation of Turbulent Combustion. Ann. Rev. Fluid Mech., 38(1), 453-482.

10. Ihme, M., \& Pitsch, H. (2008). Prediction of 
extinction and reignition in nonpremixed turbulent flames using a flamelet/progress variable model. Combust. Flame, 155(1-2), 90-107.

11. Ihme, M., Cha, C. M., \& Pitsch, H. (2005). Prediction of local extinction and re-ignition effects in non-premixed turbulent combustion using a flamelet/progress variable approach. Proc. Combust. Inst., 30(1), 793-800.

12. Cabra, R., Chen, J. H., Dibble, R. W., Karpetis, a. N., \& Barlow, R. S. (2005). Lifted methane-air jet flames in a vitiated coflow. Combust. Flame, 143(4), 491-506.

13. Cabra, R., Myhrvold, T., Chen, J. H., Dibble, R. W., Karpetis, A. N., \& Barlow, R. S. (2002). Simultaneous laser raman-rayleigh-lif measurements and numerical modeling results of a lifted turbulent $\mathrm{H} 2 / \mathrm{N} 2$ jet flame in a vitiated coflow. Proc. Combust. Ins., 29, 1881-1888.

14. Dally, B. B., Karpetis, A. N., \& Barlow, R. S. (2002). Structure of turbulent non-premixed jet flames in a diluted hot coflow. Proc. Combust. Inst., 29(1), 1147-1154.

15. Yang, T., Zhang, J. The effects of the air-fuel velocity ratio on turbulent non-premixed bluff-body flames. Proceedings of the ASME 2017 Power and Energy Conference, Power Energy 2017, June 25-30, 2017, Charlotte, NC, USA.

16. Masri, A.R. and Bilger, R.W., 'Turbulent Nonpremixed Flames of Hydrocarbon Fuels Near Extinction: Mean Structure from Probe Measurements', Twenty-first Symposium (International) on Combustion, The Combustion Institute, Pittsburgh, 1988, pp. 1511-5120.

17. Liu, C., Zhang, J. Transitional Behavior in the Regime from Lifted Flames to Mild Flames, Sixteenth International Conference on Numerical Combustion, Orlando, 2017 